\title{
TEST ANALYSIS AND VERIFICATION OF THE INFLUENCE OF MILLING CUTTER BLADE SHAPE ON WOOD MILLING
}

\author{
Yang Chunmei, Liu Qingwei, Jiang Ting, Song Mingliang \\ Ma Yan, Liu Jiueing \\ Northeast Forestry University \\ Harbin, China \\ (Received May 20i9)
}

\begin{abstract}
In this paper, the influence law of cutting tools with different blade shapes in the process of wood milling was studied. Keeping the cutting speed, cutting depth, cutting width unchanged, the blade shapes of milling cutter were the research object, the cutting force, cutting vibration, and chip morphology change under different feed rate were discussed, the surface roughness of the processed material was analyzed under down milling and up milling. The results showed that when the feed rate increased from $6 \mathrm{~m} \cdot \mathrm{min}^{-1}$ to $14 \mathrm{~m} \cdot \mathrm{min}^{-1}$, the cutting force in up milling was less than that in downing milling, the cutting vibration of upright milling cutter with spiral curved blade was the smallest, it increased gradually in the range of $13.6 \mathrm{~m} \cdot \mathrm{s}^{-2}-27.4 \mathrm{~m} \cdot \mathrm{s}^{-2}$ in up milling. On the whole, the surface roughness of the workpiece in down milling was better than that in up milling. The experimental study on the cutter milling blade shapes had a guiding significance for improving the precision of surface machining and provided a theoretical reference for the selection of process parameters in the milling process.
\end{abstract}

KEYWORDS: Milling cutter blade, wood cutting, cutting parameter, cutting force.

\section{INTRODUCTION}

Wood is a kind of natural polymer material which composed of complex organic matters, it is a typical heterogeneous anisotropic material, and widely used in furniture manufacturing, handicraft carving, home decoration and other fields (Ma 2007, Ramasamy and Ratnasingam 2010). Milling is one of the main methods of wood surface processing, and it is also the key link of product profile processing (Song et al. 2006, Engin et al. 2000). In order to obtain the high surface quality when wood processing, the forming surface of the workpiece is usually processed with milling cutter blade at one time, which with good surface smoothness and high production 
efficiency (Deng et al. 2014, Li 2008, Eblagon et al. 2007). In the milling process, cutting force, cutting vibration and chip formation are directly affected by the type of the milling cutter blade (Zhu 2015, Päivinen and Heinimaa 2003, Bayoumi and Bailey 1985), and in a cutting layer, the greater the change in cutting force, the greater the mechanical shock on the blade (Zhang et al. 2011, Âbele et al. 2013). Therefore, it is great significance to master the milling properties of wood for optimizing milling parameters, reducing tool wear and improving machining technology.

In recent years, domestic and foreign scholars had studied the milling cutter in the process of wood milling. Jung et al. (2011) provided an effective method to calculate the cutting load from the geometric angle of cutter blade, which is used to predict the area where the dimension error is too large due to the increase of cutting force and cutting load in the processing process, so as to reduce the occurrence of tool fracture or excessive deflection. Palmqvist et al. (2003) studied the changing rules of the parallel cutting force and the normal cutting force on the tool tip when cutting parameters changed in the milling process, and found out the optimal set of normal force parameters to avoid wood damage. Ekevad et al. (2012) studied the effects of different geometric shapes of cutter teeth and cutting direction on the transverse cutting force when cutting wood with six kinds of serrated tools. Jiang et al. (1994) discussed the cutting performance of cutting blade through the cutting force experiment, and provided the methods to improve the cutting performance of the milling cutter from the aspects of tool material, cutting blade structure and tool geometric angle. Zhang et al. (2010) studied the influence of the same tool wear condition on the cutting force under the same cutter parameter, and discussed the influence mechanism. Zhao et al. (2015) studied the influence of cutting parameters on milling composite force, and established the milling force model by response surface design test, which provided theoretical basis for optimizing the selection of cutting parameters, controlling and predicting milling force.

At present, the research on wood milling performance mainly focuses on tool material, tool geometric angle, cutting parameters and other aspects (Zhang 2011, Aknouche et al. 2009, Guo et al. 2009). There are few studies on the influence of milling cutter blade structure on wood milling from the published literature (Guo et al. 1999). The paper used single factor experiment to discovery the influence of milling cutter blade on surface quality and milling performance under different cutting conditions, which provided reference for improving the stability of machining quality and selection of forming tools.

\section{MATERIAL AND METHODS}

\section{Experiment materials}

The machine tool in experiment was from MIKRON UCP710 CNC milling machining center. The test tools selected three typical end milling cutters, which were often used in wood milling produced by the Germany Leitz company. The Fig. 1 presents the cutting tools in test, and tools parameters are shown in Tab. 1. At the same time, the solid wood of Fraxinus mandshurica was selected as the experimental material with the size (length $\times$ width $\times$ thickness) of $500 \times 120 \times 20 \mathrm{~mm}$, moisture content of $9 \%$, and density of $0.532 \mathrm{~g}^{\mathrm{cm}}{ }^{-3}$. 


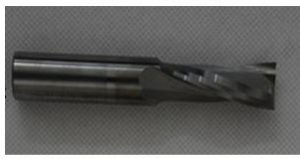

(a)

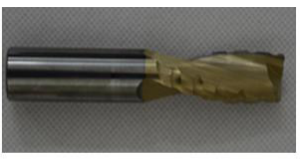

(b)

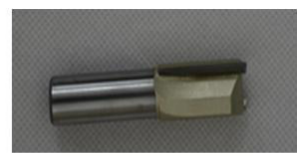

(c)

Fig. 1: Cutting tools in test: (a) The integral cemented carbide upright milling cutter with spiral blade, (b) The integral cemented carbide upright milling cutter with spiral curved blade, (c) The integral cemented carbide upright milling cutter with straight blade.

Tab. 1: Type and parameters of the wood milling tool.

\begin{tabular}{|c|c|c|c|c|c|c|}
\hline Name & Type & Material & $\begin{array}{c}\text { Outside } \\
\text { diameter } \\
\text { of cutting } \\
\text { blade(mm) }\end{array}$ & $\begin{array}{c}\text { Shank } \\
\text { diameter } \times \\
\text { length } \\
(\mathbf{m m} \times \mathbf{m m})\end{array}$ & $\begin{array}{c}\text { Tool } \\
\text { length } \\
\mathbf{( m m )}\end{array}$ & $\begin{array}{c}\text { Tooth } \\
\text { number }\end{array}$ \\
\hline a $\begin{array}{c}\text { Upright milling cutter } \\
\text { with spiral blade }\end{array}$ & 042761 & $\begin{array}{c}\text { cemented } \\
\text { carbide }\end{array}$ & $\varphi 16$ & $\varphi 16 \times 50$ & 100 & $\mathrm{Z}=2$ \\
\hline b $\begin{array}{c}\text { Upright milling cutter } \\
\text { with spiral curved } \\
\text { blade }\end{array}$ & 240202 & $\begin{array}{c}\text { cemented } \\
\text { carbide }\end{array}$ & $\varphi 16$ & $\varphi 16 \times 50$ & 100 & $\mathrm{Z}=2$ \\
\hline c $\begin{array}{c}\text { Upright milling cutter } \\
\text { with straight blade }\end{array}$ & 072106 & $\begin{array}{c}\text { cemented } \\
\text { carbide }\end{array}$ & $\varphi 16$ & $\varphi 16 \times 50$ & 90 & $\mathrm{Z}=2$ \\
\hline
\end{tabular}

\section{Experimental methods}

Wood is a kind of anisotropic biological material, in the milling process, chip thickness is changed from large to small during down milling, and chip thickness is from small to large transformation during up milling ( $\mathrm{Su}$ et al. 2002). Therefore, conducted experimental research to the above three tools, with the feed rate as the change vector and other parameters fixed, the comparative experiments were carried out respectively according to the cutting methods of down milling and up milling, and the influence rules of different cutting tools on the milling process were analyzed (Yan. et al. 2002 and Guo et al. 2011), the Tab. 2 presents milling parameters.

Tab. 2: Wood milling experiment parameters.

\begin{tabular}{|c|c|c|c|c|}
\hline & $\begin{array}{c}\text { Cutting speed } \\
v_{c}\left(\mathrm{~m}^{\mathrm{min}} \mathbf{m}^{-1}\right)\end{array}$ & $\begin{array}{c}\text { Feed rate } \\
f\left(\mathrm{~m} \cdot \mathrm{min}^{-1}\right)\end{array}$ & $\begin{array}{c}\text { Cutting depth } \\
a_{p}(\mathrm{~mm})\end{array}$ & $\begin{array}{c}\text { Cutting width } \\
a_{e}(\mathrm{~mm})\end{array}$ \\
\hline 1 & 600 & 6 & 20 & 4 \\
\hline 2 & 600 & 10 & 20 & 4 \\
\hline 3 & 600 & 14 & 20 & 4 \\
\hline
\end{tabular}

\section{RESULTS AND DISCUSSION}

\section{The effect of the tool blade shape on the cutting force}

In order to explore the effect rule of cutter blade shape on the cutting force, the milling forces in three directions of XYZ under different feed rate in down and up milling conditions are 
statistically analyzed. The Fig. 2 presents a histogram of the change of cutting force with feed rate for $a, b$ and $c$ cutting tools when cutting speed $v_{c}=600 \mathrm{~m} \cdot \mathrm{min}^{-1}$, cutting depth $a_{p}=20 \mathrm{~mm}$ and cutting width $a_{e}=4 \mathrm{~mm}$, the down milling status is shown in Fig. 2a, the up milling status is shown in Fig. 2b. It can be seen from the figure that during down milling, with the increasing of feed rate, the composite forces in $\mathrm{X}, \mathrm{Y}$ and $\mathrm{Z}$ directions of each tool have a gradually increasing trend. Because the blade types of cutters $\mathrm{a}$ and $\mathrm{b}$ are spiral edge, the cutting force $F_{z}$ in the $\mathrm{Z}$ direction of these two blades is greater than $F_{x}$ and $F_{y}$. In the case of up milling, when the feed rate is $6 \mathrm{~m} \cdot \mathrm{min}^{-1}$, c tool emerges a sudden force in the $\mathrm{X}$ direction during cutting, which may be caused by the hard point of the material encountered in the cutting process, so it is not discussed. In addition, with the increase of the feed rate, the cutting force of the three tools in various directions also increases gradually, and the trend is more regular.

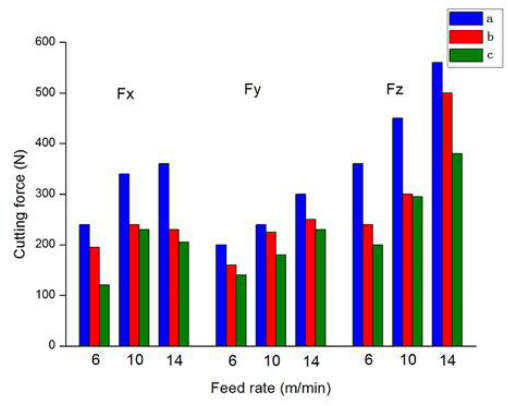

(a)

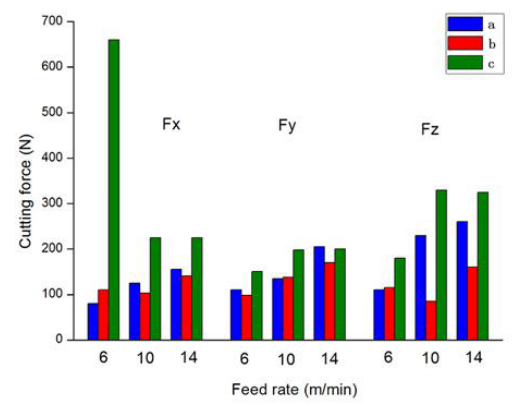

(b)

Fig. 2: The effect rules of the feed rate on the cutting forces of the cutting tools $a, b$, and $c$ in milling: (a) Down milling, (b) Up milling.

After measurement and calculation, the cutting composite force of the cutting tools in down milling is shown in Tab. 3. In the case of the same feed rate and the same direction, the cutting composite force of three kinds of tools shows a gradual decrease trend, and the value of the cutting composite force has a relation: $F_{a}>F_{b}>F_{c}\left(F_{a}\right.$ - the cutting composite force of the tool a; $F_{b}$ - the cutting composite force of the tool $\mathrm{b} ; F_{c}$ - the cutting composite force of the tool c; the same below).

Tab. 3: Cutting composite force of the three cutting tools in the down-milling.

\begin{tabular}{|c|c|}
\hline Tool type & Cutting composite force (N) \\
\hline $\mathrm{a}$ & $497-637.5$ \\
\hline $\mathrm{b}$ & $389.6-648.7$ \\
\hline $\mathrm{c}$ & $272.3-509.8$ \\
\hline
\end{tabular}

The cutting composite force of the three cutting tools in up milling is shown in Tab. 4 . Excluding the sudden change of the tool $\mathrm{c}$ in the $\mathrm{X}$ direction, in the case of the feed rate is $6 \mathrm{~m} \cdot \mathrm{min}^{-1}$, the cutting composite force value of the three cutting tools does not fluctuate much. When the feed rate increases from $10 \mathrm{~m} \cdot \mathrm{min}^{-1}$ to $14 \mathrm{~m} \cdot \mathrm{min}^{-1}$, the value of the cutting composite force has a relation: $F_{c}>F_{a}>F_{b}$. Due to the cutting blade of the tool $b$ is the unique helical blade and wave blade, this cutting blade improves the cutting efficiency and optimizes the cutting effect in the cutting process. Compared with the straight line blade of the tool $\mathrm{c}$ and the helical blade of the tool $\mathrm{a}$, the tool $\mathrm{b}$ also plays a role in reducing the cutting force in the up milling process. 
Tab. 4: Cutting composite force of the three cutting tools in the up-milling.

\begin{tabular}{|c|c|}
\hline Tool type & Cutting composite force (N) \\
\hline a & $253.1-496.7$ \\
\hline b & $167-523.3$ \\
\hline c & $286.6-550.8$ \\
\hline
\end{tabular}

In the condition of the same feed rate, by analyzing and comparing the cutting force under the two milling methods, it can be known that the cutting force of the cutting tools $\mathrm{a}$ and $\mathrm{b}$ in down milling is greater than that in up milling under the same cutting parameters. The cutting force of the tool $\mathrm{c}$ in the process of down milling is less than that in the process of up milling. Therefore, it can be seen that the milling method also has an impact on the cutting force when the tool is cutting the material.

\section{The effect of the tool blade shape on the cutting vibration}

In order to explore the effect rule of cutter blade shape on the cutting vibration, the cutting vibration in three direction of XYZ under different feed rate in down and up milling conditions are statistically analyzed. The Fig. 3 presents a histogram of the change of cutting vibration with feed rate for $a, b$ and $c$ cutting tools when cutting speed $v_{c}=600 \mathrm{~m} \cdot \mathrm{min}^{-1}$, cutting depth $a_{p}=20 \mathrm{~mm}$ and cutting width $\mathrm{a}_{\mathrm{e}}=4 \mathrm{~mm}$, the down milling status is shown in Fig. 3a, the up milling status is shown in Fig. 3b. It can be seen from the figure that during down milling, due to the increase of the cutting force caused by the increase of the feed rate, the vibration values in $\mathrm{X}, \mathrm{Y}$ and $\mathrm{Z}$ directions of each tool have a gradually increase tended. In the case of the tool a, the cutting vibration in the $\mathrm{X}$ direction (feed direction) will be relatively small when the feed rate is $6 \mathrm{~m} \cdot \mathrm{min}^{-}$ 1 , and the main sources of the cutting vibration are $\mathrm{Y}$ direction (cutting width direction) and $\mathrm{Z}$ direction. Similar to the down milling process, the vibration value of the three directions also increases gradually.

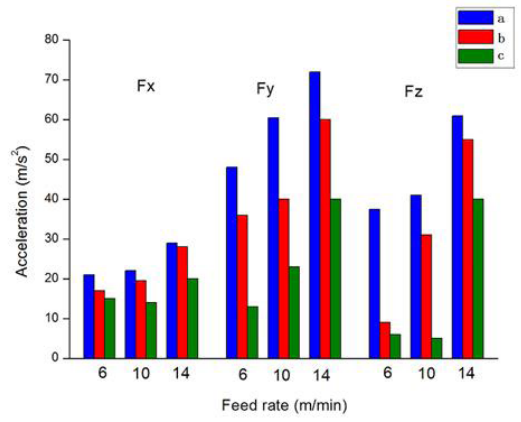

(a)

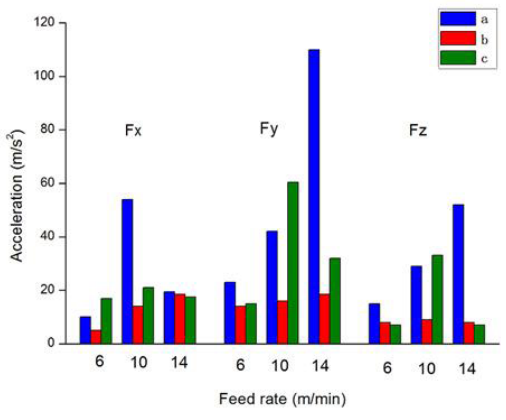

(b)

Fig. 3: The effect rules of the feed rate on the cutting vibration of the cutting tools $a, b$, and $c$ in milling: (a) Down milling, (b) Up milling.

After measurement and calculation, the sum of cutting vibration in $\mathrm{X}, \mathrm{Y}$ and $\mathrm{Z}$ directions during down milling is obtained; the total vibration value is shown in Tab. 5. In the case of the same feed rate and the same direction, the cutting vibration of the three kinds of tools shows a gradually decrease trend, and the relationship is: the cutting vibration of the tool $a$ is greater than the tool $b$, and the cutting vibration of the tool $\mathrm{b}$ is greater than the tool $c$, but the difference is relatively less. 
Tab. 5: Cutting vibration values of the three cutting tools in the down-milling.

\begin{tabular}{|c|c|}
\hline Tool type & Cutting vibration $\left(\mathbf{m} \cdot \mathbf{s}^{-\mathbf{2}}\right)$ \\
\hline $\mathrm{a}$ & $63.8-99.1$ \\
\hline $\mathrm{b}$ & $41.9-90.8$ \\
\hline $\mathrm{c}$ & $22.1-61.6$ \\
\hline
\end{tabular}

The total vibration value of the three cutting tools in up milling is shown in Tab. 6. Under the same cutting parameters, the cutting vibration of the tool $a$ is slightly larger than the tool $b$, but the difference is very subtle. However, due to the reasons of the unique wave blade design of the tool $b$, the cutting vibration of the tool $\mathrm{b}$ is significantly smaller than that of the tools $a$ and $c$.

Tab. 6: Cutting vibration values of the three cutting tools in the up-milling.

\begin{tabular}{|c|c|}
\hline Tool type & Cutting vibration $\left(\mathbf{m} \cdot \mathbf{s}^{-\mathbf{2}}\right)$ \\
\hline $\mathrm{a}$ & $30.3-125.3$ \\
\hline $\mathrm{b}$ & $13.6-27.4$ \\
\hline $\mathrm{c}$ & $23-70.4$ \\
\hline
\end{tabular}

\section{Effect of the tool blade on chip formation}

In order to explore the effect rule of the cutter blade shape on the chip formation, the chip formation under different feed rate in down and up milling conditions are statistically analyzed. The Fig. 4 presents the change diagram of chip formation of $a, b$ and $c$ cutting tools in down milling states when cutting speed $v_{c}=600 \mathrm{~m} \cdot \mathrm{min}^{-1}$, cutting depth $a_{p}=20 \mathrm{~mm}$ and cutting width $a_{e}=4 \mathrm{~mm}$. The chips of tool $a$ and $c$ show spiral curled shape, and the chips produced by tool $c$ are generally more straight. The chips of the tool $b$ presents irregular spiral, and have certain radian and present different size stripes. It can be known from the test that the size of the tool chip will increase with the feed rate increasing.

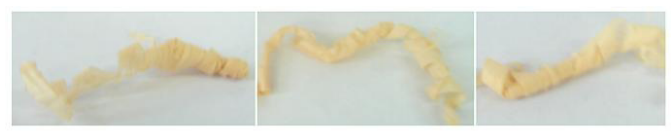

(a) Chip shapes of the tool a in the down milling.

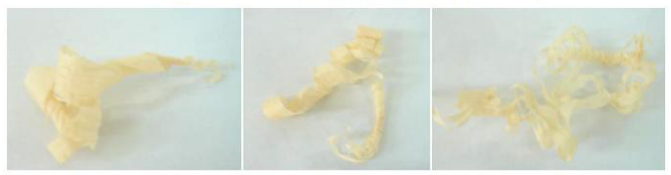

(b) Chip shapes of the tool $b$ in the down milling.

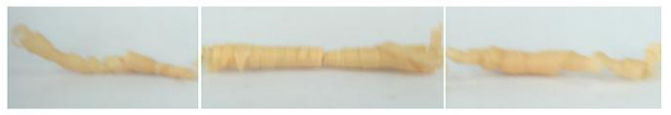

(c) Chip shapes of the tool $b$ in the down milling

Fig. 4: The chip shapes comparison of the different tool milling in the down-milling.

The Fig. 5 presents the chip formation at different feed rate with different cutting tools in up milling state. Similar to the down milling state, the chips of the tool $a$ and $c$ increase with the feed rate increasing, and the chips of the tool $b$ appear scattered strip. 


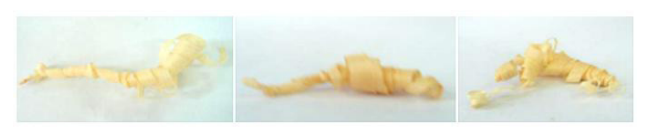

(a) Chip shapes of the tool a in the up milling

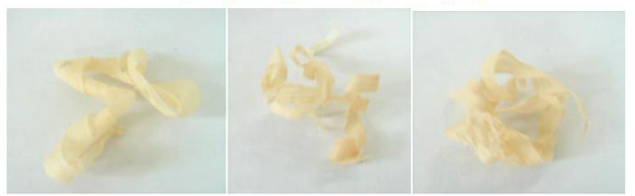

(b) Chip shapes of the tool $b$ in the up milling

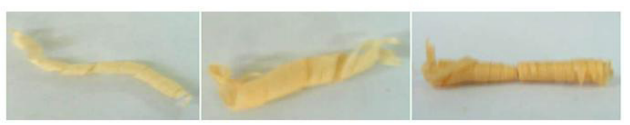

(c) Chip shapes of the tool $b$ in the up milling

Fig. 5: The chip shapes comparison of the different tool milling in the up-milling.

\section{Effect of the tool blade on the surface quality of the workpiece}

The surface quality of the cut-in and the cut-out of the workpiece cut by the tools $a, b$, and $c$ is measured and compared by the TR240 surface profile tester. The Fig. 6 presents the rule of the surface roughness of the tool $a, b$, and $c$ with the changing of feed rate in the down milling.

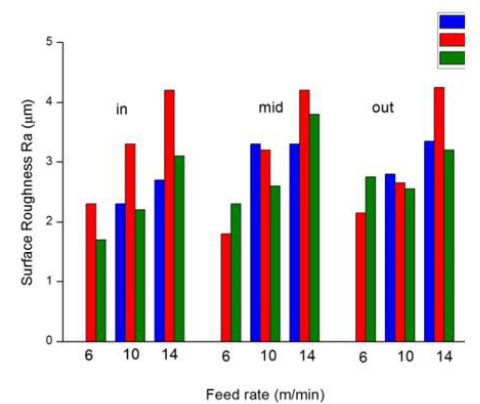

(a)

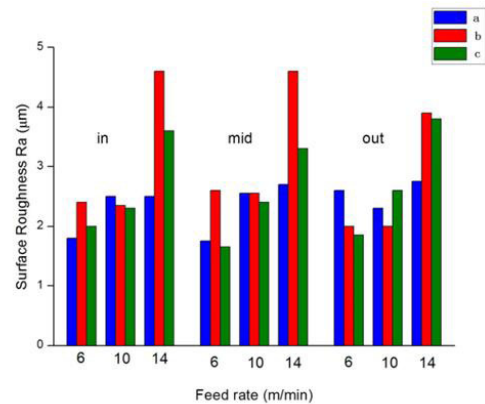

(b)

Fig. 6: The effect rules of the surface roughness of the cutting tools $a, b$, and $c$ with the changing of feed rate in the down milling: (a) Down milling, (b) Up milling.

Each group of experiments collected the surface of the cutting-in, cutting-mid, and cuttingout to detect, so as to reach the purpose of minimizing the error and ensure the accuracy of the measurement data. When the specimen is processed, keeping the cutting speed $v_{c}=600 \mathrm{~m} \cdot \mathrm{min}^{-1}$, cutting depth $a_{p}=20 \mathrm{~mm}$ and cutting width $a_{e}=4 \mathrm{~mm}$ remain unchanged, the feed rate is set at $6 \mathrm{~m} \cdot \mathrm{min}^{-1}, 10 \mathrm{~m} \cdot \mathrm{min}^{-1}$, and $14 \mathrm{~m} \cdot \mathrm{min}^{-1}$. The result shows that the surface roughness appears gradually increasing trend with the increase of the feed rate when the three tools perform down milling and up milling, and the value of the surface roughness increases obviously when the feed rate reaches $14 \mathrm{~m} \cdot \mathrm{min}^{-1}$. By comparison under the same feed rate, the surface roughness of the workpiece of the tool $a$ is slightly better than that of the tool $c$. Due to the non-uniformity of material removal in the process of the wave blade cutting, the surface roughness of the tool a and 
$\mathrm{c}$ are obviously better than that of the tool $\mathrm{b}$. In the whole, the surface roughness of the workpiece after the down milling is better than that after up milling.

\section{CONCLUSIONS}

In this paper, single factor milling tests were carried out on the tools with different cutting blades, and the influence rules of three kinds of cutting tools on cutting force, cutting vibration, chip state and surface quality were compared under different feed rate. The following conclusions were drawn from the comparison and observation:

(1) With the increase of feed rate during down milling, the cutting composition force of the three cutting tools increases gradually in all directions, and the trend is more regular. At the same feed rate and the same direction, the cutting composition force of the three kinds of cutting tools successively presents a decreasing trend in the up milling. The unique helical blade and wave blade of tool $\mathrm{b}$ can reduce the cutting force in the up milling.

(2) In the downing milling, the cutting vibration produced by the helical blade and straight blade with vibration damping groove structure is less than that of the helical blade without damping groove structure. In the up milling, because the upright milling cutter with spiral curved blade has a wavy damping groove, which can reduce the cutting resistance and minimize the cutting vibration.

(3) Through the experiment on chip deformation mechanism, the influence relationship between the cutting parameters on chip morphology is obtained. The shape of the chip is related to the cutter blade shape, and the helical blade produces helical chip, while the straight blade produces linear chip, and the helical blade with the vibration groove produces block chip.

(4) It can be seen from the detection of workpiece surface quality, the feed rate has a great influence on the surface roughness. In the case of down and up milling, the surface roughness of the workpiece increases with the increase of feed rate, and the surface quality of the milling tool with helical blade is better. In contrast, the milling surface roughness of the helical blade without damping groove is smaller.

\section{ACKNOWLEDGEMENTS}

The research was supported by Research on Key Equipment for Multi-interface Machining of Small Diameter Lumber (2018YFD06003054); and Fundamental Research Funds for the Central Universities (2572018CG06). The authors would like to take this opportunity to express their sincere appreciation.

\section{REFERENCES}

1. Ābele, A., Mioncinskis, U., Tuherm H., 2013: Determination of cutting tool wear and surface roughness of straight milled aspen wood. Pro Ligno 9(4): 751-759.

2. Aknouche, H., Outahyon, A., Nouveau, C., Marchal. R., Zerizer, A., Butaud, J.C., 2009: Tool wear effect on cutting forces: In routing process of Aleppo pine wood. Journal of Materials Processing Technology 209(6): 2918-2922. 
3. Bayoumi, A.E., Bailey, J.A., 1985: Comparison of the wear resistance of selected steels and cemented carbide cutting tool materials in machining wood. Wear 105(2): 131-144.

4. Deng, N., Li, C., Liu, M., Lin, L., 2014: Research on processing technology of wave milling. Tool Technology 48(8): 102-103.

5. Engin, S., Altintas, Y., Ben, A.F., 2000: Mechanics of routing medium density fiberboard. Forest Products Journal 50(9): 65-69.

6. Ekevad, M., Cristóvāo, L., Marklund, B., 2012: Lateral cutting forces for different tooth geometries and cutting directions. Wood Mate-rial Science \& Engineering 7(3): 126-133.

7. Eblagon, F., Ehrle, B., Graule, T., Kuebler, J., 2007: Development of silicon nitride/silicon carbide composites for wood-cutting tools. Journal of the European Ceramic Society 27(1): 419-428.

8. Guo, F., Wang, Q.Y., Lei, W.M., 1999: Numerical control grinding technology and tool position calculation for front face of spiral blade cutter. China Mechanical Engineering 19(1): 10-11.

9. Guo, X.L., Liu, H.N., Cao, P.X., 2011: Formation mechanism of chip flow in the milling of wood based materials. Journal of Nanjing Forestry University (Natural Science Edition) 35(5): 74-78.

10. Guo, X.R., Lu, H.M., Gou, X.L., Du D.F., 2009: Study on virtual simulation of wood cutting process based on three-dimensional model and geometric parameter optimization for wood tool. Machine Tool \& Hydraulics 37(6): 30-33.

11. Jung, Y.H., Kim, J.S., Hwang, S.M., 2001: Chip load prediction in ball-end milling. Journal of Materials Processing Technology 111(1): 250-255.

12. Jiang, J.P., Huang, K.Z., Ai, X., Ding, Z.H., Gao, H.D., 1994: Discussion on improving cutting performance of wood forming milling cutter. Journal of Qingdao Institute of Architecture and Engineering 1: 1-5.

13. Li, L., 2008: Choice and application of wood milling tools. Wood Processing Machinery 19(5): 47-52.

14. Ma, Y., 2007: The new development of theory research in design of timber cutter abroad. Forestry Machinery and Woodworking Equipment 35(3): 4-8.

15. Palmqvist, J., 2003: Parallel and normal cutting forces in peripheral milling of wood. Holz als Roh-und Werkstoff 61(6): 409-415.

16. Päivinen, M., Heinimaa, T., 2003: The effects of different hand tool blade coatings on force demands when cutting wood. International Journal of Industrial Ergonomics 32(3): 139-146.

17. Ramasamy, G., Ratnasingam, J., 2010: A review of cemented tungsten carbide tool wear during wood cutting processes. Journal of Applied Sciences 10(22): 2799-2804.

18. Song, C., Song, K.F., Song, H.M., 2006: The microscopic process at the cutting edge of the cutting tool during wood cutting. International wood industry 36(4): 19-25.

19. Su, W.C., Wang, Y., 2002: Effect of the helix angle of router bits on chip formation and energy consumption during milling of solid wood. Journal of Wood Science 48(2): 126-131.

20. Yan, B., Xu, A.P., Zhang, D.W., Huang, T., Zeng, Z.P., 2002: A new milling force model of spiral edge ball end milling cutter is presented. China Mechanical Engineering 13(2): 160-163.

21. Zhu, H.B., 2015: Influencing factors of milling vibration vased on cutting parameters and tool wear. Mechanical Research and Application 4: 57-59.

22. Zhang, Z.K., Peng, X.R., Li, W.G., Zeng, J., Wang, B.G, 2011: Influence of cutting parameters on cutting forces in wood sawing. China Wood Industry 25(6): 7-9. 
23. Zhang, J.L., Li, B.Z., Pang, J.Z., 2010: Study on cutting force characteristics in tool wear process. Manufacturing Technology and Machine Tools 5: 111-113.

24. Zhao, Y.C., Tu, J.X., 2015: Influence of cutting parameters on milling force of ebony wood. Machine Design and Manufacturing Engineering 5: 1-5.

25. Zhang, Z.C., 2011: Face milling cutter for plane machining and its parameter selection. Metal Working (cold working) 21: 43-46.

Yang Chunmei, Liu Qingwei, Jiang Ting, Song Mingliang, Ma Yan*

Northeast Forestry University

Forestry and Woodworking Machinery Engineering Technology Center

Haping 6Th Street, Haping Road, Heilongjiang Province

Harbin, I50040

CHINA

*Corresponding author: myan@vip.163.com

\author{
Liu Jiveing* \\ Northeast Forestry University \\ College of Mechanical and Electrical Engineering \\ Harbin, I5004O \\ China
}

*Corresponding author: nefujdljq@163.com 